To begin with an emotional debate about GM techniques is to look down the wrong end of the telescope. Policymakers in developing countries should instead start with the problem and make their own decisions about the balance of pros and cons of different solutions in their local context, guided by biosafety legislation.

The level of hunger and malnutrition people are currently facing in Africa and Asia, and the fact that a much higher proportion of the population in both continents depends on agriculture for their livelihoods, means that it makes little sense for decisions on GM crops to be overly influenced by European perspectives. First, by the end of the century, the United Nations estimates that less than $10 \%$ of the world's population will be living in Europe. Second, in Europe, where the benefits of better crop yields are slight, the risks (although largely theoretical, and in some cases, arguably irrational) may dominate in a risk-benefit analysis. It is worth noting that where GM technology is essential to products that Europe is short of, including some medicines, fewer concerns are expressed.

Genetic engineering is not essential, or even useful, for all crop improvements. But in some cases, it helps to improve yields and nutritional value, and reduces the risks and costs associated with the overuse of fertilizers, pesticides and water. Excluding any technology that can help people to get the food and nutrition that they need should be done only for strong, rational and locally relevant reasons.

Christopher J. M. Whitty is chief scientific adviser at the UK Department for International Development (DFID), London, and professor of international health at the London School of Hygiene \& Tropical Medicine, UK. Monty Jones is executive director at the Forum for Agricultural Research in Africa, Accra, Ghana. Alan Tollervey is head of agriculture research at DFID. Tim Wheeler is deputy chief scientific adviser at DFID, and professor of crop science at the University of Reading, UK. e-mail:c-whitty@dfid.gov.uk

1. Owino, O. Nature http://dx.doi.org/10.1038/ nature.2012.11929 (2012).

2. Renkow, M. \& Byerlee, D. Food Policy 35 391-402 (2010).

3. Varshney, R. K., Bansal, K. C., Aggarwal, P. K., Datta, S. K. \& Craufurd, P. Q. Trends Plant Sci. 16, 363-371 (2011).

4. Hotz, C. et al. J. Nutr. 142, 1871-1880 (2012).

5. Tang, G. et al. Am. J. Clin. Nutr. 96, 658-664 (2012).

6. Kijima, Y., Sserunkuuma, D. \& Otsuka, K. Dev. Econ. 44, 252-267 (2006).

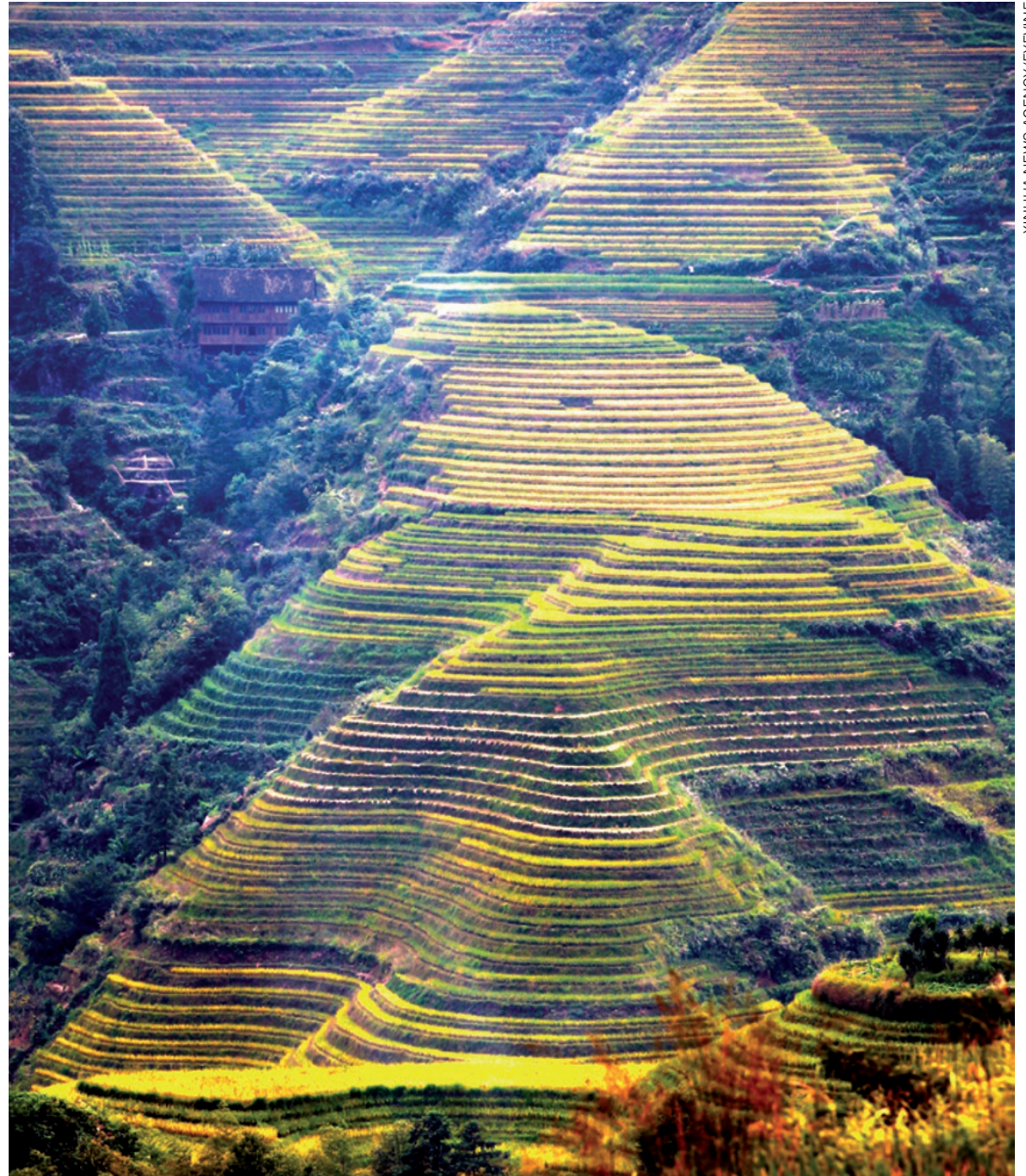

Terraced fields in China, where researchers are pushing crop yields close to their biophysical limits.

\section{An experiment for the world}

$\mathrm{F}$ or the past two decades, commentators have hailed genetically modified (GM) crops as the magic bullet that will solve the world's food crisis. Yet obtaining the drastically bigger yields needed to feed a growing and increasingly wealthy global population - without further depleting soils, destroying natural habitats and polluting air and water - will

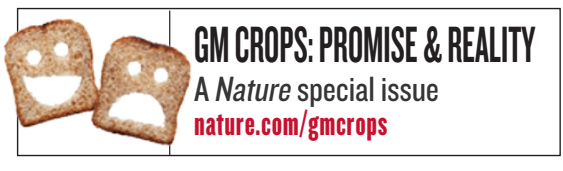

demand an all-embracing approach.

China is taking steps towards such a strategy, and so offers an extraordinary laboratory for the rest of the world. In 2003-11, the country increased its cereal production by about $32 \%$ (more than double the world average ${ }^{1}$ ), largely by improving the performance of its least-efficient farms. Yet in the next 
two decades, $30-50 \%$ more food will be needed to meet China's projected demand ${ }^{2}$. The country has little spare land, and water shortages are reaching crisis levels in some areas. Added to this, excessive fertilizer use is a major contributor to air pollution ${ }^{3}$ - itself a leading risk factor in hundreds of thousands of premature deaths each year. The overuse of fertilizer is also causing numerous lakes, rivers and coastal regions to become clogged with algal blooms, especially in south China.

Driven by an urgent need to both produce more food and lessen the environmental impact of agriculture - and with government money available - Chinese scientists are working out how to push crop yields close to their biophysical limits. We believe that to obtain the greatest yields for the lowest economic and environmental costs, developing and developed economies should look to China for guidance on how to integrate diverse fundamental research, including that on genetic modification, with experimental and modelling approaches.

\section{FERTILE FARMS}

In the United States, there is slightly more than half a hectare of farmed land for every person. Just one-tenth of a hectare is available for each of China's 1.3 billion people. More than $90 \%$ of the country's 230 million farms are tiny - a typical farm in the North China Plain, for instance, is around 7 metres wide and 160 metres long ${ }^{4}$. Owners of such farms often have other jobs in nearby towns or cities, and it rarely makes economic sense for them to invest in machinery or yearround crop or soil management when the plot is so small. Meanwhile, continual agricultural use has depleted many Chinese soils of their natural nutrient reserves, and excessive fertilization has acidified them ${ }^{5}$. Overall, less than $50 \%$ of the fertilizer applied to fields actually goes to the crops for which it was intended ${ }^{6}-$ much of the rest leaches into the environment.

In the face of such challenges, agricultural scientists in China are trying to boost yields of the nation's staple grains - maize (corn), rice and wheat - by analysing fields as ecosystems. In experimental plots and in field studies on farms, they are tracking inputs and outputs such as water, nutrients, genetic material, solar and fossil energy, and muscle power from humans and animals. For instance, by chemically testing rain and irrigation water and monitoring the amount of fertilizer or manure added, researchers can estimate the amount and types of nutrient entering the system. The various inputs and outputs are optimized, to produce the greatest yield for the least resources and the lowest nutrient losses, by manipulating conditions and approaches in
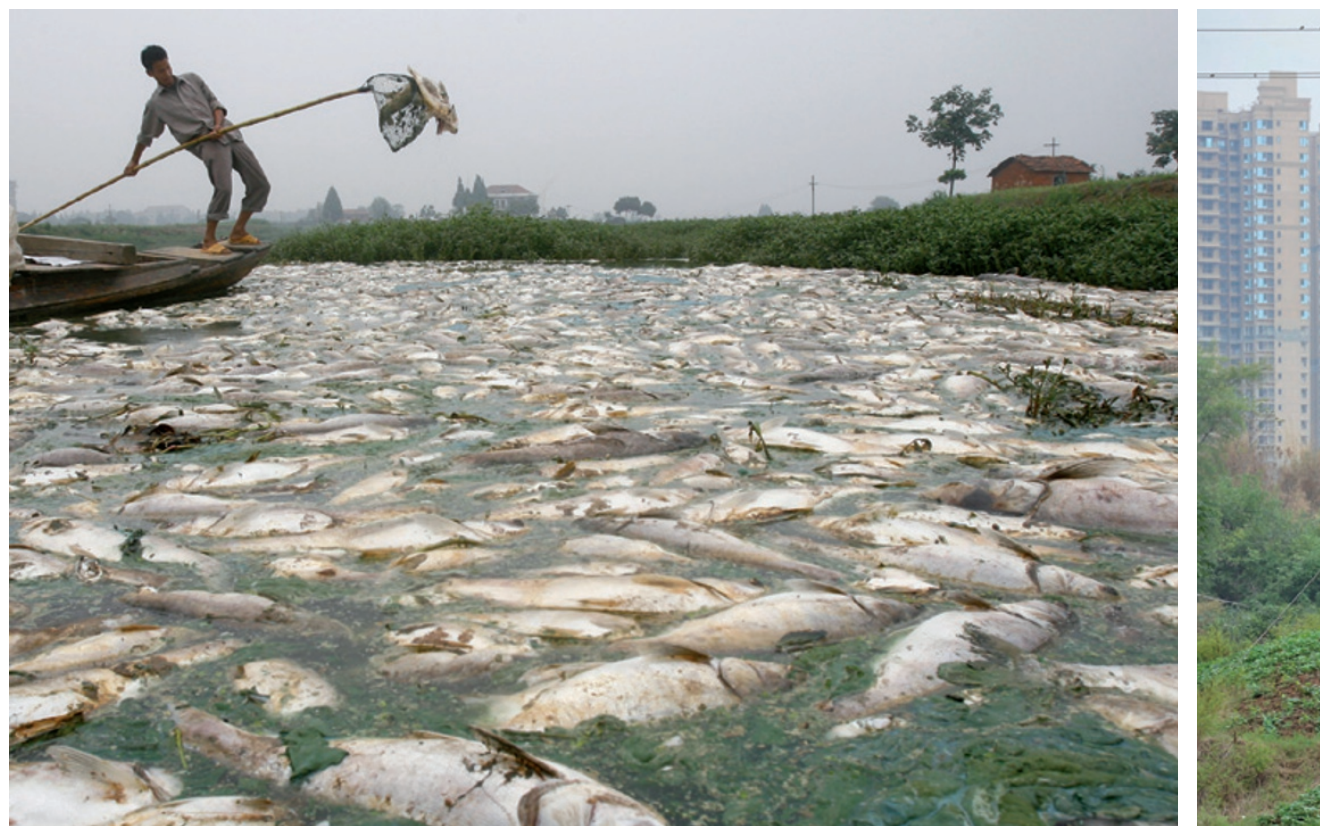

A lake in Hubei province clogged with algae, caused by excess fertilizer running off nearby fields. replicate experimental plots, and by following plots over years. For instance, in a project involving 16 universities and institutes led by the China Agricultural University in Beijing, researchers have studied the growth of wheat, maize and rice for the past 5 years in nearly 500 plots across 11 provinces. So far, they have increased both the yields and the efficiency with which the crops use nitrogen in these plots by $30-50 \%$ (unpublished data).

The development of new crop varieties and hybrids is one of several areas of fundamental research that feed into this approach, with transgenic technology becoming an increasingly important element in recent years. For example, by growing $B t$ cotton - the first GM crop approved for commercial use in China - farmers have increased yields since 1997 by nearly $6 \%$ and reduced the use of insecticides by around $80 \%$ (ref. 7). Although the Chinese public is wary of GM food crops, in 2008 China's central government established a 12-year research and development initiative for GM crops at a cost of 25 billion renminbi (US $\$ 3.7$ billion at the time). With funding matched by the government's provincial counterparts ${ }^{8}$, the initiative includes China's staple food crops.

Agricultural scientists are also drawing on studies of how water, nutrients and solar energy are allocated to making leaves, stems and grain; of the effect of soil structure and chemistry on roots; and of how biological, chemical and geological processes determine soil properties. Such research provides insight into the best times to add fertilizer, or the planting dates and densities that will optimize the use of water and solar energy. Recent studies on root-zone nutrient management in more than 5,000 experimental plots across 20 provinces, for instance, enabled a group led by the China Agricultural University to increase yields by $12 \%$ on average over a 7 -year period. The effort also reduced fertilizer use by $24 \%$ (ref. 9).

To integrate all the relevant information

\section{MORE FOR LESS}

Using farm designs informed by modelling, Chinese agricultural researchers are increasing yields in experimental plots and in farm studies while reducing the amount of resources used and nutrients lost.
Maize produced Maize per kilogram of
fertilizer

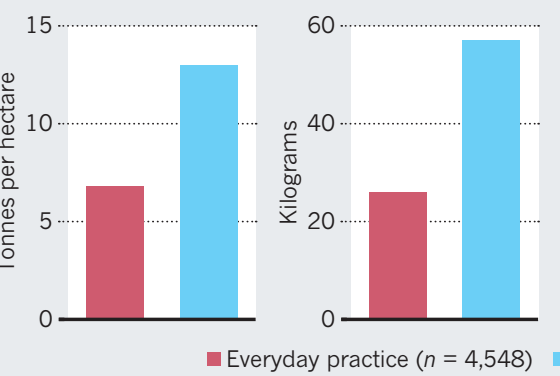

Maize per millimetre of water consumed

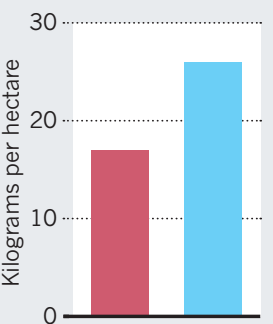

Excess nitrogen applied

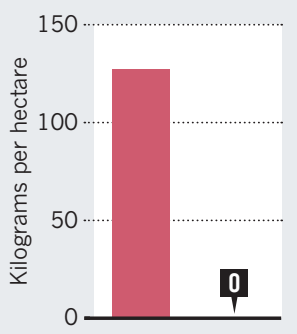



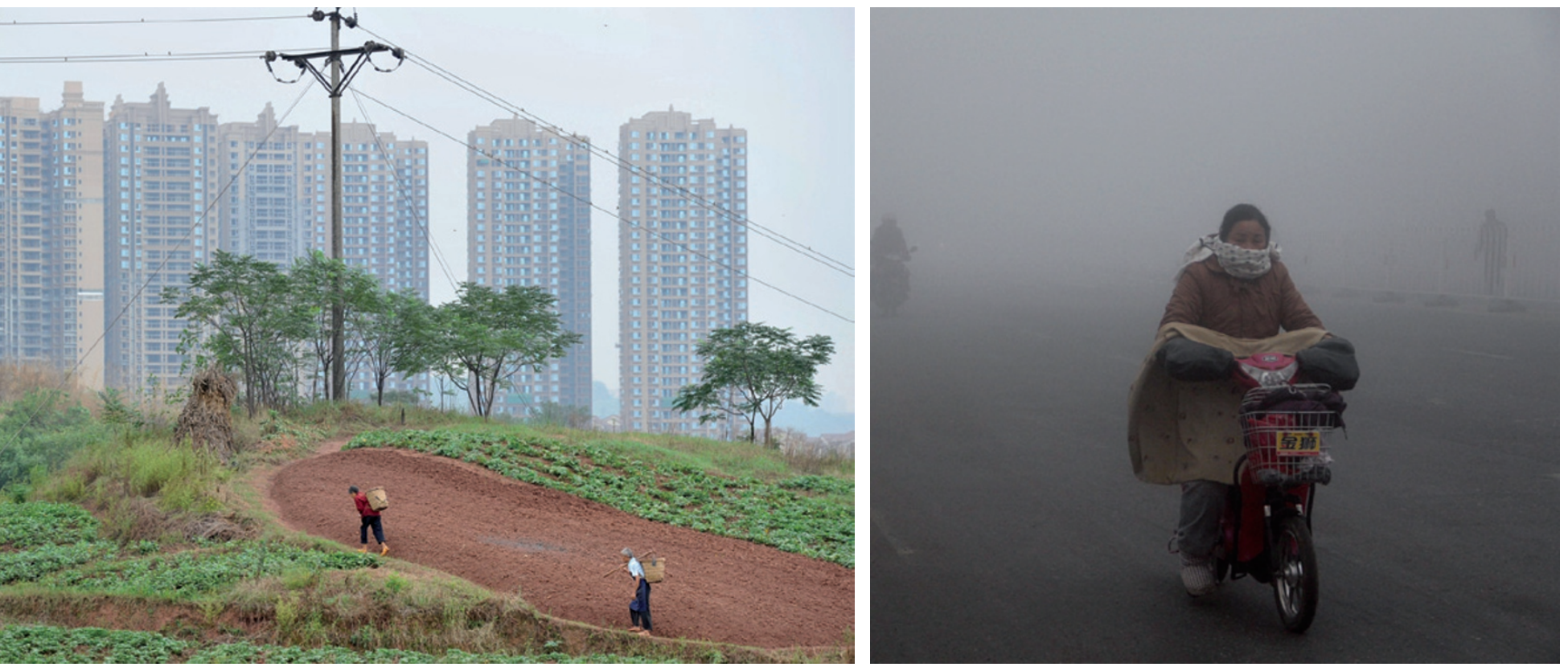

Most Chinese farms are tiny, making it hard to boost yields while reducing environmental costs such as air pollution.

$\frac{\infty}{\infty}$ and produce results that can be applied to China's diverse agricultural regions - from the subtropical wet south to the North China Plain and the cooler northeast - agricultural scientists are feeding information on climate, soil conditions, water supply and their variability into models. The 'optimal' genetic varieties and management approaches selected through modelling are evaluated by measuring factors such as the growth of crops and their uptake of nutrients, in experimental plots or in field studies.

These measurements can then be used to improve the performance of the models, which in turn are used to further enhance yields ${ }^{4}$ (see 'More for less').

China is not the first to use this ecosystemmodelling approach. In Europe and the United States, where the method was first developed, farmers and researchers mainly use it to fine-tune established practices. Chinese scientists, by contrast, are integrating models and experiments with nationwide monitoring networks to redesign agricultural systems on a vast scale.

\section{DEMONSTRATING SUCCESS}

By taking what they have learnt from experimental plots to real farms, Chinese scientists have already reduced fertilizer usage to economically optimal levels while maintaining yields. For instance, in a study using 49 field experiments on real farms in the North China Plain and Taihu region, researchers from various institutions were able to reduce the amount of fertilizer used by $30-60 \%$ between 2003 and 2006 without reducing yields of rice, wheat or maize ${ }^{6}$. (That study underpinned some of the other research on fertilizer use and efficiency already mentioned.) Other results using the modelling-ecosystem

approach are also promising.

To realize its goal of a $30-50 \%$ hike in yields nationally, the Chinese government has more than tripled its investment in agricultural research since 2000, from 7 billion renminbi to 24.4 billion renminbi in 2009 - or from $0.36 \%$ to $0.66 \%$ of gross domestic product. And it has allocated 3 billion renminbi a year since 2008 to a national network of organizations for developing modern agricultural technology that, at its inception, involved 50 universities, 340 institutes, 200 companies and more than 2,000 agricultural scientists.

Even so, it remains a daunting challenge to transfer research results into farming practice across so many small farms. To support the transfer of knowledge and technology, the Chinese government is funding more than 12,000 researcher-led demonstrations of cropand soil-management approaches throughout the country. It

\section{"Other developing countries should seek guidance from Chinese scientists and systems."}

has established several programmes and subsidies: for instance, last year, it invested 1.5 billion renminbi to pay for soil testing to guide farmers about how much fertilizer to add to their soils and when.

Chinese agricultural research must keep pace with extraordinary societal changes as well as growing demands for food, resources and environmental protection. As millions of people pour into cities such as Shanghai, Beijing and Guangzhou to find work, the agricultural heartlands of the north and south will increasingly struggle with labour shortages. Plots might become combined, with individuals managing several hectares. Also, as people continue to eat more meat and dairy items, imports of feed products will further increase; for example, in 2012, nearly $80 \%$ of the soya beans used in China were imported (58.4 million tonnes).

China's system of millions of tiny farms is unique. Yet the scope, quality and trajectory of agricultural research in China, together with its willingness and need to tackle fundamental environmental challenges, mean that other developing countries, such as India or Bangladesh, should seek guidance from Chinese scientists and systems. Farmers in Europe, North America, New Zealand and Australia can also learn from China's approach. In the face of climate change, pushing yields to the limit while sparing resources and reducing environmental consequences is a crucial goal for all.

Fusuo Zhang is director, and Xinping Chen is professor at the Center for Resources, Environment and Food Security, China Agricultural University, Beijing, China. Peter Vitousek is professor in the Department of Biology, Stanford University, California, USA.

e-mail:zhangfs@cau.edu.cn

1. FAO Statistical Yearbook 2012 (Food and Agriculture Organization of the United Nations, 2012); available at go.nature.com/nfmwxx.

2. Zhang, F. et al. J. Environ. Qual. 40, 1051-1057 (2011).

3. Liu, X. et al. Nature 494, 459-463 (2013)

4. Chen, X. P. et al. Proc. Natl Acad. Sci. USA 108, 6399-6404 (2011)

5. Guo, J. H. et al. Science 327, 1008-1010 (2010).

6. Ju, X. T. et al. Proc. Natl Acad. Sci. USA 106, 3041-3046 (2009)

7. Huang, J., Hu, R., Rozelle, S., Qiao, F. \& Pray, C. E. Aust. J. Agric. Resour. Econ. 46, 367-387 (2002).

8. Qiu, J. Nature 455, 850-852 (2008).

9. Zhang, F. et al. Adv. Agron. 116, 1-40 (2012). 